Bangladesh J. Zool. 49 (1): 69-82, 2021

ISSN: 0304-9027

eISSN: $2408-8455$

\title{
EXPANDING DENGUE VECTORS THROUGH THE BORDER OF DHAKA CITY: VECTOR BREEDING GROUNDS IN GAZIPUR CITY CORPORATION, BANGLADESH
}

\author{
G. M. Saifur Rahman ${ }^{*}$ and Tahmina Akter ${ }^{2}$ \\ Department of Zoology, Faculty of Life and Earth Science, National University, \\ Gazipur, Bangladesh
}

\begin{abstract}
With global expansion of vector borne diseases, dengue has emerged as a big health crisis and social problem in recent years in Bangladesh. Despite its endemicity since 2000, very few studies were conducted outside of the Capital Dhaka city regarding vector breeding status. Within this dark situation, the year 2019 reported the ever highest number of dengue cases of 101,354. Of them about $50 \%$ were from out of Dhaka. To reduce this burden, keeping the vector population density under threshold level is must. In the present entomological study, 100 houses were checked randomly from five areas of Gazipur City Corporation (GCC) during the month of September in 2019. Both of the Aedes vectors were found in all areas, but Aedes aegypti population was dominant. Rooftop garden and under construction site were identified as the most important vector breeding sites. Highly urbanized area (SA2) produced the highest and suburban area (SA4) produced the lowest Breteau Index (BI) of 110 and 15 respectively. The overall House Index (HI) and Breteau Index (BI) of the study areas were 16 and 49 respectively. Four kinds of containers, namely; cemented tank, drum, big earthen pot (chari) and buckets contained about 80 percent of immature Aedes and identified as key container among the positive containers. The Said study has identified comparatively higher number of Ae. aegypti breeding, which is potential for triggering any major outbreak. Further, large-scale surveillance in all administrative wards with a larger sample may indicate the real picture of vector infestation situation throughout the municipality.
\end{abstract}

Key words: Aedes, mosquito, dengue, Gazipur, Key container, Bangladesh.

\section{INTRODUCTION}

Aedes mosquitoes are recognized vector of many arboviruses in tropical and subtropical countries like Bangladesh. Out of all the species under genera Aedes, Aedes aegypti and Ae. albopictus are mainly liable for causing chikungunya, dengue and zika in South Asian region.

*Author for Correspondence: <gmsaifur20@yahoo.com>, 2Department of Zoology, Faculty of Biological Sciences, Jahangirnagar University, Savar, Dhaka, Bangladesh

(a)2021 Zoological Society of Bangladesh DOI: https://doi.org/10.3329/bjz.v49i1.53683 
About 400 million dengue infections occur all over the world annually, of which $70 \%$ cases are from Asia (Bhatt et al. 2013). This threat is increasing day by day as seen in the previous years. This rate has increased more than 30 -folds during last 5 decades (Bhatt et al. 2013). Hence, around half of the world's population is at risk.

Currently, Aedes-borne diseases have become a burning health issue in Bangladesh from municipality to district and Thana headquarters. Dengue was known as Dacca fever in Dhaka city corporation area (DCC) during its first report in 1964 (Aziz et al. 1967). In 2000 Bangladesh experienced its first epidemic of dengue after more than three decades of sporadic transmission. Then 5551 cases were reported with 93 casualties (Rahman et al. 2002). After that a significant number of dengue cases are reported in a regular basis (Mahmood and Mahmood 2011, Farhana et al. 2014) including the ever-highest number of 101,354 cases in 2019 (DGHS 2020). All four serotypes and their different genotypes of dengue viruses are circulating here (Aziz et al. 2002, Yunus et al. 2002, Muraduzzaman et al. 2018, Shirin et al. 2019). Sporadic cases of chikungunya fever were also being reported from the capital city, its suburbs and some remote areas since 2008 (Chowdhury et al. 2012). Zika patients were also identified in 2016. However, this aberrant situation is increasing day by day with the spreading of the cases into new areas with expanding its vector mosquito throughout the country round the year (DGHS 2020).

Within two Aedine species, Ae. aegypti was widely known principal vector of dengue, breeds in urban domestic environments. Its population increases and spreads due to quick urbanization, rapid human population growth, population migration, ongoing development work, erratic weather with longer wet season, poor urban infrastructure with unreliable water supply, increasing volume of solid wastes including discarded containers that make suitable larval habitats in urban, sub-urban and even some rural areas (Dieng et al. 2012, Saifur et al. 2013). The secondary vector, Ae. albopictus mosquito was known as Asian tiger mosquito. Earlier, it was abundant in the suburban and rural environment throughout the country. But in the current environmental situation with high human population density has impacted on its behavior and habitats. Therefore, this species might be replaced with its counterpart in many areas as seen in other countries (Hawley 1988).

The availability or circulation of multiple genotypes and serotypes of dengue virus, abundance of vector mosquito population and different environmental factors determine the severity of dengue. As a relatively new city corporation (1 $1^{\text {th }}$ out of twelve municipalities in Bangladesh formed in 2016), Gazipur City 
Corporation (GCC) does not have an update data on its vector mosquito population and their habitats. A small-scale sporadic study was conducted since 2014-2017 and primarily reported the presence of Ae. aegypti in few locations of GCC (Saifur et al. 2016). Since the distribution of vector types and abundances depend on the advancement of urbanization and industrialization, GCC has much developed in this regard in the recent years, which might have created many areas in different administrative wards suitable for vector breeding that is undiscovered till to date. Due to its geographical (northern border of the capital city Dhaka) and commercial importance to the national economy, its population is rapidly increasing without ensuring social securities and facilities. Additionally, huge gathering and movement of multiple ethnic population due to having numerous educational institutions including national and international universities, internationally reputed research institutions and garments business hub have accelerated urbanization process and poses a threat to spread different disease-causing viruses with the presence of proper carrier and vectors. To understand the real picture related to the vector-borne diseases in GCC's urban and suburban areas, the continuous study is essential, which can help to take early steps regarding its management.

Therefore, the current study was conducted to provide some basic information regarding the occurrence and distribution of Aedes vector mosquitoes and their key breeding habitats in GCC. This will encourage the City Corporation authority to take necessary steps to combat the vector population in an organized way by setting proper surveillance and integrated vector management programs.

\section{MATERIAL AND METHODS}

Study Area: Vector breeding situation of Aedes mosquitoes in five areas of GCC viz. Tongi Bazar (SA1), College gate are (SA2), Gazipura are (SA3), Borobari (SA4) and Board Bazar are (SA5) were studied during the month of September, 2019. The Gazipur city corporation is within an area of 329.53 square kilometer. It is the largest and 11th city corporation of Bangladesh. The North end of Dhaka, the capital city of Bangladesh is bordered with this city. It is rapidly industrialized and highly populated with more than 3.5 million inhabitants. Due to small- and large-scale industries from different sectors majoring growing garment industries, the population is increasing rapidly in this city from neighbouring districts. To give them shelter, an unplanned urbanization is speeding up. A lot of slum type residences without proper sanitation support and water supply system as well as a number of moderate to multi-storied 
buildings are giving shelter to the city dwellers in this mostly plain land. Day by day the marshy and vegetative areas are decreasing rapidly with increasing unplanned establishment. A new trend of launching roof top gardens is also increasing on multistor buildings nowadays. There is no water supply system. So dwellers use underground water. The following five areas (Figure 1) with urban and semi urban natures of the municipality were selected for the present study.

Entomological study: The immature stages of Aedes species were carried out in 5 different areas of GCC as described above in 2019. The samples were collected from twenty randomly selected houses in each study area once in the month of September (considered as dengue peak season and the end month of monsoon in Bangladesh). Indoor and outdoor containers and water holding pockets were checked for the presence of Aedes mosquitoes adopting others (Ahmed et al. 2007, Saifur et al. 2013). The content of mosquito immature positive containers was collected and poured into plastic containers. The containers were properly labeled with date of collection, area code, house identification code and container code. Large water holding containers i.e. wells, water tanks, artificial ponds, etc. were sampled for two to five minutes using fish net (Richards 2005).

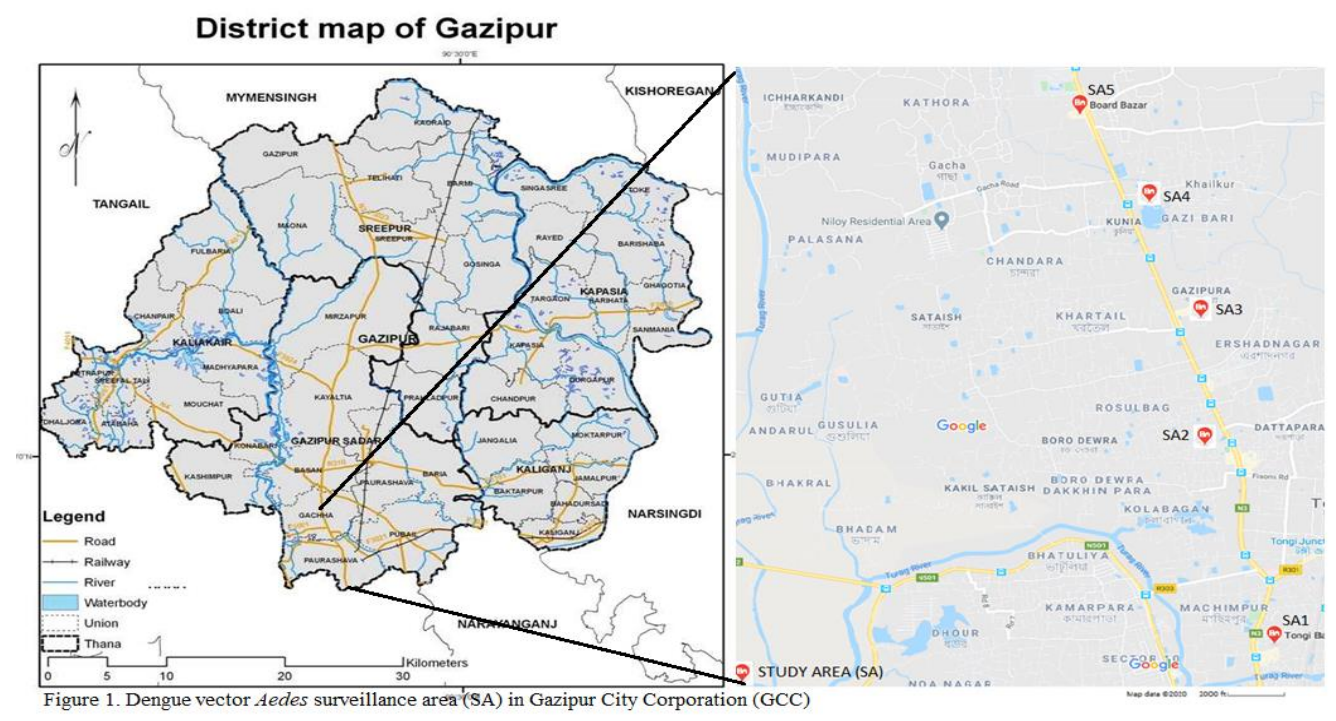

The samples were carried to the laboratory of National University, Gazipur. Identification of larval samples were done by using compound microscope up to species level according to the standard keys (Tinker and Stojanovich 1962, Slaff 
and Apperson 1989). The pupal population were reared into adults at a $26 \pm 2^{\circ} \mathrm{C}$ of room temperature, $76 \pm 5 \%$ of $\mathrm{RH}$ and $12: 12 \mathrm{~h}$ of photoperiod. Then they were identified under microscope (Tanaka et al. 1979). The dead pupae were identified according to Harrison (2005). The total number of immature were counted and recorded against the container and area codes. Then a database was made with all necessary information for subsequent statistical analyses.

Data collection and analysis: The data of immature holding containers were recorded separately. The water holding containers were considered as wet container (WC) and wet containers having with immature Aedes mosquito were positive containers (PC). Area-wise House Indicex or HI (percentage of houses with immature Aedes PC) and Breteau Indicex or BI (number of PC per 100 houses). Collected data were analyzed using JASP version 0.12.2.0. Spearman's correlation test was used to determine the significant relation among the productivity of different positive containers. t-test identified relations between two types of positive key containers.

\section{RESULTS AND DISCUSSION}

Dengue vector status in different study area: One hundred houses from five study sites were sampled for Aedes immature. Among them 16 houses were found to breed dengue vector mosquitoes, which produced an overall $\mathrm{HI}$ and BI of 16 and 49 respectively. All study sites harbored Aedes immature and produced variable indices. The highest indices were HI 25 and BI 110 in SA2 followed by SA5, SA1, SA3 and SA4. Immature Ae. aegypti were predominant in all areas. It was the sole agent in urbanized areas (SA1, SA2 and SA5), whereas Ae. albopictus was found to breed in relatively lower urbanized areas (SA3 and SA4). The immature Aedes indices in all areas were much higher than the standard risk level of both $\mathrm{HI}$ and BI of 5 (Table 1). The present indices of the vector mosquitoes in all study sites at the end of the monsoon period profoundly prove their higher density and wide distribution.

Table 1. The immature Aedes density in different study areas

\begin{tabular}{llccccccc}
\hline $\begin{array}{c}\text { Study } \\
\text { Area }\end{array}$ & \multicolumn{2}{c}{ No of Houses } & \multicolumn{2}{c}{$\begin{array}{c}\text { No. of } \\
\text { Containers }\end{array}$} & \multicolumn{2}{c}{$\begin{array}{c}\text { Aedes } \\
\text { Indices }\end{array}$} & \multirow{2}{*}{$\begin{array}{c}\text { No. of } \\
\text { Immature }\end{array}$} & $\begin{array}{c}\text { Vector } \\
\text { Species }\end{array}$ \\
\cline { 2 - 6 } & Checked & Positive & Wet & Positive & HI & BI & & \\
\hline SA1 & 20 & 3 & 20 & 8 & 15 & 40 & 3337 & Ae. aegypti \\
SA2 & 20 & 5 & 37 & 22 & 25 & 110 & 9332 & Ae. aegypti \\
SA3 & 20 & 2 & 14 & 4 & 10 & 20 & 817 & Both \\
SA4 & 20 & 2 & 10 & 3 & 10 & 15 & 235 & Both \\
SA5 & 20 & 4 & 18 & 12 & 20 & 60 & 3220 & Ae. aegypti \\
Total & 100 & 16 & 99 & 49 & 16 & 49 & 16941 & \\
\hline
\end{tabular}

Both: Ae. aegypti and Ae. albopictus 
Vector breeding habitat: In the present small-scale study, fifty percent wet containers were found to be positive, among them only four containers contained Ae. albopictus immature others contained Ae. aegypti (Fig. 2A). No container contained mixed population. All Ae. albopictus immature holding containers were found at both, outdoors and rooftops. Instead, breeding of $A e$. aegypti mosquitoes were observed in all locations (Fig. 2B). This widens distribution of this vector mosquito in all study areas suggest its wider breeding and adaptation nature.

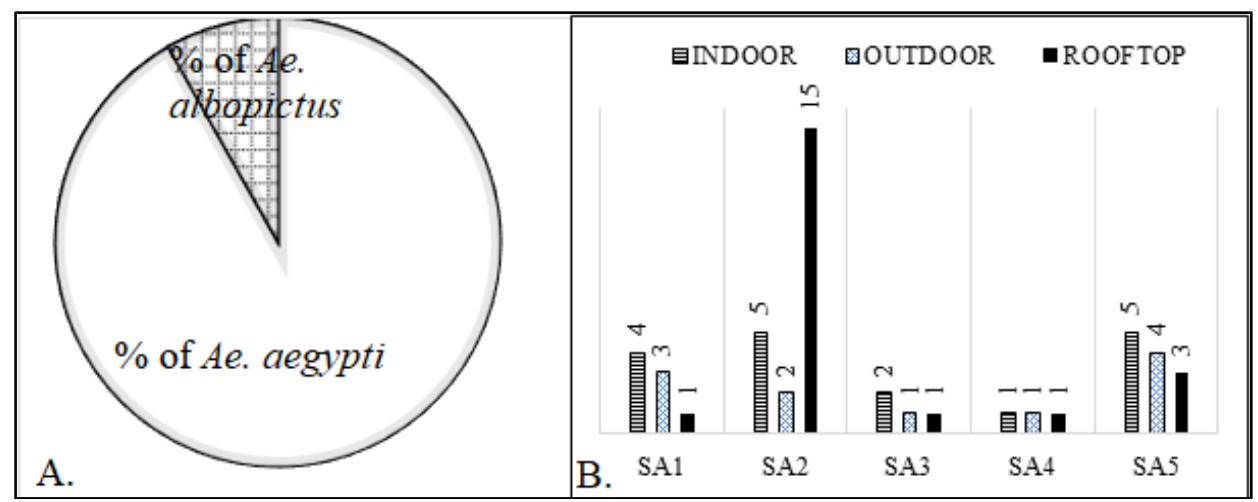

Fig. 2. Positive container situation in GCC. A. Ratio of positive containers containing different dengue vectors; B. Positive container abundance in different locations of study areas.

There were Six types of positive containers found in study areas. The maximum number of PCs was found in SA2 followed by SA5, SA1, SA3 and SA4 (Table 1). Among the positive containers two types of containers produced the maximum $(75-86 \%)$ immature Aedes in each area. Therefore, they are considered the key containers of that specific area (Table 2). Overall four containers, namely; cemented tank, drum, earthen pot and bucket are promising key container.

Table 2. Different positive containers in the study area

\begin{tabular}{|c|c|c|c|c|c|}
\hline Name of PCs & Placing of PCs & $\begin{array}{l}\text { Study } \\
\text { Area }\end{array}$ & Key Containers & $\begin{array}{l}\text { \% of Total } \\
\text { Immature }\end{array}$ & Species \\
\hline Earthen Pot & Rooftop (RT) & SA1 & Drum, Bucket & 75 & Ae. aegypti \\
\hline $\begin{array}{l}\text { Cemented } \\
\text { Tank }\end{array}$ & Indoor (IN) & SA2 & $\begin{array}{l}\text { Earthen Pot, } \\
\text { Cemented Tank }\end{array}$ & 86 & Ae. aegypti \\
\hline Drum & IN/Outdoor & & & & \\
\hline Buckets & Indoor & SA3 & $\begin{array}{l}\text { Cemented Tank, } \\
\text { Drum }\end{array}$ & 79 & Ae. aegypti \\
\hline Roof gutter & IN/Outdoor & SA4 & Drum, Bucket & 77 & Ae. aegypti \\
\hline Flower vase & IN/Outdoor/RT & SA5 & $\begin{array}{l}\text { Cemented Tank, } \\
\text { Bucket }\end{array}$ & 82 & Ae. aegypti \\
\hline
\end{tabular}




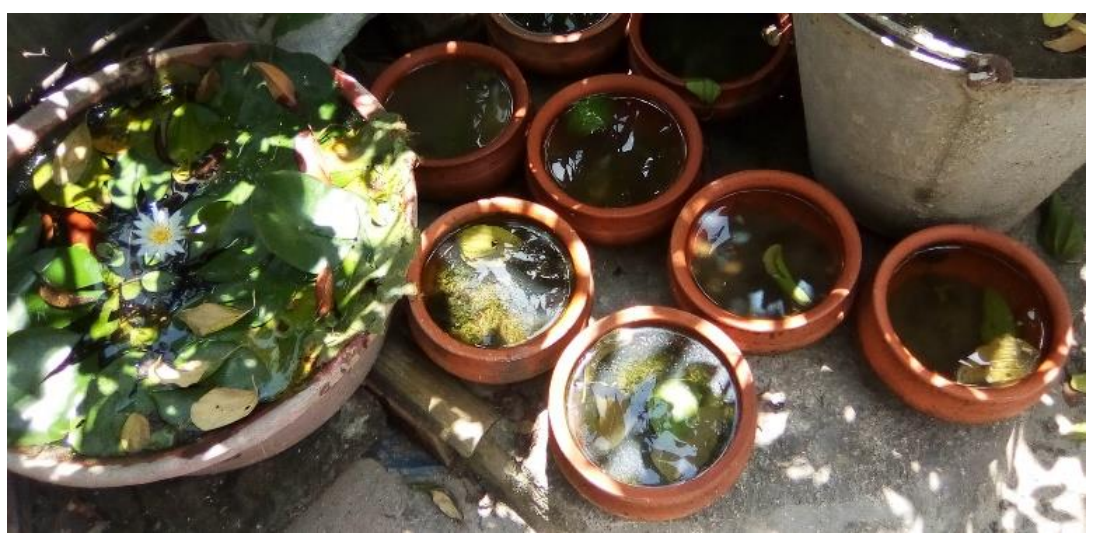

Fig. 3. Earthen pots on rooftop gardening with immature Ae. Aegypti

Key containers: Mainly four types of container namely, cemented tank or water reservoir, drum, big earthen pot (chari) and buckets singly or together with other three types of containers contained about 80 percent of immature Aedes. Therefore, they are potential breeding containers or key containers in the present study areas. But among these four types of container, cemented tank and drum produced the highest number of individuals ( $\mathrm{t}=1.326, P=0.277)$. Other containers singly harbored significantly lower numbers of immature (Table 4), but they were numerous than the first two kinds of containers. All containers in different study sites contained heterogeneous stages of immature Aedes that suggested these sites are continuous breeding sites of the dengue vector mosquitoes (Table 3). Among the key containers, the earthen pots were used for rooftop gardening (Fig. 3) and cemented tanks were found mainly in under construction houses as well as rooftop fish culture. Both of the places were prolific vector breeding place due to the inattentiveness of household owners and construction authority.

Table 3. Mosquito immature productivity of key containers in GCC

\begin{tabular}{|c|c|c|c|c|c|c|c|}
\hline \multirow{2}{*}{$\begin{array}{l}\text { Name of } \\
\text { +ve } \\
\text { container }\end{array}$} & \multirow{3}{*}{$\begin{array}{c}\text { No. of } \\
\text { immature }\end{array}$} & \multirow{3}{*}{$\begin{array}{c}\text { No of +ve } \\
\text { container ( } \% \text { of } \\
\text { imma/container) }\end{array}$} & \multicolumn{4}{|c|}{ Aedes Immature } & \multirow[t]{3}{*}{ Species } \\
\hline & & & $2^{\text {nd }}$ & $3^{\text {rd }}$ & $4^{\text {th }}$ & Pupae & \\
\hline & & & Instar & Instar & Instar & & \\
\hline $\begin{array}{l}\text { Cemented } \\
\text { Tank }\end{array}$ & 4378 & $4(8)$ & 1691 & 1370 & 1104 & 213 & Ae. aegypti \\
\hline Drum & 3515 & $4(6.25)$ & 987 & 1305 & 1045 & 178 & Ae. aegypti \\
\hline Buckets & 587 & $10(0.4)$ & 112 & 207 & 177 & 91 & Ae. aegypti \\
\hline Earthen Pot & 5367 & $25(1.5)$ & 1209 & 2218 & 1720 & 220 & Ae. aegypti \\
\hline Total & 13847 & & 3999 & 5100 & 4046 & 702 & \\
\hline
\end{tabular}


Table 4. Statistical analysis among different key containers

Paired Samples T-Test

\begin{tabular}{lllllc}
\hline & & & $\mathrm{t}$ & $\mathrm{df}$ & $\mathrm{p}$ \\
\hline Cemented Tank & - & Drum & 1.326 & 3 & 0.277 \\
Cemented Tank & - & Bucket & 3.307 & 3 & 0.045 \\
Cemented Tank & - & earthen Pot & 3.211 & 3 & 0.049 \\
Drum & - & Bucket & 3.509 & 3 & 0.039 \\
Drum & - & earthen Pot & 3.735 & 3 & 0.033 \\
Bucket & - & earthen Pot & -2.697 & 3 & 0.074 \\
\hline
\end{tabular}

Note. Student's t-test.

\section{DISCUSSION}

The current study has identified high density of Aedes aegypti in urban and sub-urban areas of GCC. In addition sub-urban areas produce some Ae. albopictus mosquitoes. In a previous study, one of the present urban sites (SA5) reported both, Ae. aegypti and Ae. albopictus mosquitoes (Saifur et al. 2016). Then no dengue cases were reported from this municipality. During the present study a total of 101,354 patients were reported all over the country, where 49 percent were from out of Dhaka. Of them, among Dhaka division, about $18.7 \%$ cases were from GCC (DGHS 2020, Somokal 2019). This information indicates the positive relationship of the present dengue vector density and reported dengue cases. Previously GCC did not maintain any record of dengue cases as well as its vector density. But, so far dengue vector mosquito was present there. It is like as DCC, where dengue was reported earlier in 1964 but continuous outbreak started from 2000 (Aziz et al. 1967, Yunus 2000, Rahman et al. 2002, Mahmood and Mahmood 2011, Farhana et al. 2014). In GCC, though we conducted a small scale study but it is clear that the dengue vectors are available here and the principal dengue vector Ae. aegypti is increasing with the progress of urbanization. The same feature is observed all over the world regarding the vector distribution and spread of dengue cases.

In this latest study the highest $\mathrm{HI}$ and BI was identified as 25 and 110 respectively though overall indices were a bit lower, which was a HI of 16 and a BI of 49. All these indices are higher than the expected threshold level of Aedes population. Earlier, comparatively higher HI and BI of 5 would be considered as the threshold level (Connor et al. 1923, Soper 1967, Brown 1977), but since the late 1990s, much lower indices of around 1 of both $\mathrm{HI}$ and BI is considered as dangerous for DENV transmission in many countries (Pontes et al. 2000, Chang et al. 2015). We need to achieve these lowest indices of vector population to reduce our Aedes-borne disease burden. 
In case of the population of secondary dengue vector, the Asian tiger mosquito Ae. albopictus, which is decreasing gradually in the urban areas compared with the earlier study in 2016 (Saifur et al. 2016) and the present study in suburban areas. Among five-study areas, three urbanized areas were free from this vector mosquito. Even no container was observed with mixed breeding. Recently the same picture was seen in different areas of Dhaka south city corporation (Saifur and Chowdhury 2020). During the dengue outbreak in 2000, a lot of Ae. albopictus immature were found in different areas of DCC (Ahmed et al. 2007). But, in a recent study conducted by us (unpublished data), we found all areas majoring Ae. albopictus have been shifted or replaced by Ae. aegypti. This kind of invasion is seen in different Southeast Asian countries (Iwamura et al. 2020, Lwande et al. 2020). It also indicates the early introduction of Ae. aegypti in these areas, which was not identified in the GCC areas earlier in absence of continuous monitoring and surveillance.

The present work was conducted at the end of rainy season, in the month of September, but a good number of wet and positive containers were found. From this observation it can be assumed that in the earlier months of the monsoon produced more mosquito population that caused more infections. This statement can be justified with the total number of dengue cases in the country. The month of August generated a total of 51,734 cases all over the country and the month of September produced 17,758 cases (nearly $30 \%$ of August). It is parallel with the past record of Bangladesh, here maximum Aedes borne cases were recorded during July to September or the monsoon period (Chowdhury et al. 2012, Ahmed et al. 2007). In recent years this tradition is changing with global climate change and higher population density. The year 2019 produced dengue case round the year with the lowest number of 17 cases in March. It shows the permanency of dengue cases at least in DCC. From this scenario, it can be suggested that monitoring of Aedes population should be in continuous manner by an expert authority or organization through an effective surveillance system and operate management program according to that observation. This action should be taken for all administrative areas as the case and vector population is spreading and increasing in newer areas of both urban and rural sites. Otherwise, it will be a big challenge for us to manage vector borne diseases.

Our month-long study in 100 households identified major four types of potential breeding containers known as key containers. They were cemented tanks, drums, earthen pots and buckets. The cemented tanks were mostly found in under construction sites for curing purposes and market places for having baths. Somewhere it was on the rooftop for birds feeding, fish culture or water 
storage purposes. When they were not properly maintained and water was not changed on a weekly basis, they became potential Aedes breeding sources. Drums and buckets were found available in all kinds of houses, markets, under construction sites and in some restaurants. The earthen pots were mainly found on rooftops for gardening purposes in the present study. The above four types of containers are also common in our different cities and localities, which was reported in previous different entomological studies including capital city Dhaka (Ferdousi et al. 2015). In a previous study in one of the present study areas; construction sites, roof gutter and outdoor miscellaneous containers were reported as Aedes breeding source (Saifur et al. 2016). But the present study observed some new containers as key breeding sites. So, large scale study is essential to accurately identify the key vector breeding sites in GCC and make aware the inhabitants about them and their management techniques. As a new city corporation, GCC is operating multifaceted construction work under multiple development funds. In addition, as urbanization is progressing, so a continuous construction work is running, which may produce a lot of breeding sites of different types and vector population may become upsurge as DCC. Though, types of vector breeding sites vary according to the lifestyle of the inhabitants of an area, locality or country (Saifur et al. 2012). These similarities and dissimilarities in different tropical and sub-tropical countries also were observed in different studies (Lee 1991, Macielde-Freitas et al. 2007, Garelli et al. 2011).

To combat this present rising situation, GCC needs an organized integrated vector management system, which is completely absent meanwhile it is a new municipality. But it is the time to format this organization under expert entomologist, which is absent all of our municipalities even in the whole country. During this present epidemic situation, GCC operated an unorganized some small scale sporadic fogging activities with pyrethroid insecticides from October to December 2019, which might be ineffective due to its wrong application procedure. They applied in very limited places during the midday without considering air speed, sunlight or following any proper guideline. This situation may help in growing insecticide resistance problem.

Moreover, public awareness regarding vector biology, its habitat in GCC, identifying key containers, their proper management techniques, knowledge about the easiest management system is essential to know the city dwellers. The effective public health products should register here and make some mosquito immature control products available to the counter for public purchasing and applying. Knowledge regarding integrated vector management by general people would be very helpful in this regard. Moreover, appointing mosquito workers 
under different administrative Wards and equipped them with modern technology and techniques by proper training is necessary in different municipalities and even in district levels to manage the upcoming threats all over the country. The construction companies should have strict agreement with the land owners, companies, agencies and government to take necessary measures to reduce vector population and breeding habitats during their construction period. Since, till to date, there is no tetravalent vaccine or complete solution for dengue suppression, vector management through source reduction is the best identified practice mainly in new developing cities as well as developing countries, which should strictly follow by the authority to avoid further upsurge from this health panic.

Furthermore, as the main cities of Bangladesh are experiencing dengue problem in a continuous manner since 2000 and the vector mosquitoes are spreading from the city center to its periphery (Farhana et al. 2014, Khan and Akmed 1986, Ali et al. 2003). As a bordering city with the capital, GCC has a possibility to expand its vector population faster than any other new city. So, the Ministry of Local Government, the authorizing ministry of municipalities and the Health ministry should instruct GCC to take steps earlier to manage its vector mosquitoes. GCC authority and related organizations should conduct intensive and continuous entomological study and take proper action to manage this vital vector insect. They should follow a systematic procedure considering the universal and combined strategy by providing primary warning for forthcoming epidemics highlights functional surveillance system, public awareness and applying effective vector control techniques.

Acknowledgments: We wish to thank the National University authority and the city dwellers for their assistance to carry out the study.

\section{LITERATURE CITED}

Ahmed, T.U., Saifur, R.G.M., Bashar, K., Shamsuzzaman, M., Samajpati, S., Sultana, S., Hossain, M.I., Banu, N.N. and Rahman, M.S. 2007. Seasonal prevalence of dengue vector mosquitoes in Dhaka City, Bangladesh. Bangladesh J. Zool. 35: 205-212.

Ali, M., Wagatsuma, Y., Emch, M., and Breiman, R.F. 2003. Use of a geographic information system for defining spatial risk for dengue transmission in Bangladesh: role for Aedes albopictus in an urban outbreak. Am. J. Trop. Med. Hyg. 69: 634-340.

Aziz, M. M., Hasan, K. N., Hasanat, M. A., Siddiqui, M. A., Salimullah, M., Chowdhury, A. K., et al. 2002. Predominance of DEN-3 genotype during the recent dengue outbreak in Bangladesh. Southeast Asian J. Trop. Med. Public Health 33: 42-48. 
Aziz, M.A., Gorham, J.R. and Gregg, M.B. 1967. "Dacca fever" an outbreak of dengue. Pak. J. Med. Res. 6: 83-92, 1967.

Bhatt, S., Gething, P.W., Brady, O.J., Messina, J.P., Farlow, A.W., Moyes, C.L., et al. 2013. The global distribution and burden of dengue. Nature 496: 504-507.

Brown A.W.A. 1977. Worldwide surveillance of Aedes aegypti. Proceedings of Annual Conference California Mosquito Control Association; NY, USA, Academic Press. p. 20-25.

Chang, F.S., Tseng, Y.T., Hsu, P.S., Chen, C.D., Lian, I.B. and Chao, D.Y. 2015. Re-assess vector indices threshold as an early warning tool for predicting dengue epidemic in a dengue nonendemic country. PLoS Negl. Trop. Dis. 9(9): e0004043.

Chowdhury, F.I., Kabir, A., Das, A., Mukerrama, S.M., and Masud, S. 2012. Chikungunya fever: an emerging threat to Bangladesh. J. Medicine 13: 60-64.

Connor, M.E., and Monroe, W.M. 1923. Stegomyia indices and their value in yellow fever control. Am. J. Trop. Med. Hyg. 3: 9-19.

DGHS. 2020. Daily dengue status report. https://dghs.gov.bd/index.php/en/e-health/our-ehealtheservices/81-english-root/5200-daily-dengue-status-report. (Accessed: 29 October, 2020).

Dieng, H., Rahman, G.M.S., Abu Hassan, A., Salmah, M.R.C., Satho, T., Miake, F., Boots, M. and Sazaly A.B. 2012. The effects of simulated rainfall on immature population dynamics of Aedes albopictus and female oviposition. Int. J. Biometeorol. 56: 113-120. https://doi.org/10.1007/ s00484-011 -0402-0

Farhana, R.Z. Fatema, K.A., Khanum, H. and Akter, T. 2014. Prevalence of dengue fevers among the patients of different economic status attended at local hospital in Dhaka. Bangladesh J. Zool. 42: $161-168$.

Ferdousi, F., Yoshimatsu, S., Ma, E., Sohel, N. and Wagatsuma, Y. 2015. Identification of essential containers for Aedes larval breeding to control dengue in Dhaka, Bangladesh. Trop. Med. Hlth. 43: $253-264$.

Garelli, F. M., Espinosa, M. O., Weinberg, D., Trinelli, M. A., \& Gurtler, R. E. (2011). Water use practices limit the effectiveness of a temephos-based Aedes aegypti larval control program in northern Argentina. PLoS Negl. Trop. Dis. 5(3): e991.

Harrison, B. A. 2005. Easily seen characters to identify the pupa of Aedes albopictus in the united states. J. Am. Mosq. Control Assoc. 21: 451-454.

Hawley, W.A. 1988. The biology of Aedes albopictus. J. Am. Mosq. Control Assoc. Suppl. 1:1-40.

Iwamura, T., Guzman-Holst, A. and Murray, K.A. 2020. Accelerating invasion potential of disease vector Aedes aegypti under climate change. Nat. Commun. 11: 1-10.

Khan, M. and Ahmed, T. 1986. Dengue status in Bangladesh. Dengue News Letter, 12(11).

Lee, H.L. 1991. A nationwide resurvey of the factors affecting the breeding of Aedes aegypti (L.) and Aedes albopictus (Skuse)(Diptera: Culicidae) in urban towns of peninsular Malaysia-19881989. Trop. Biomed. 8:157-160 
Lwande, O.W., Obanda, V., Lindstrom, A., Ahlm, C., Evander, M., Naslund, J. and Bucht, G. 2020. Globe-Trotting Aedes aegypti and Aedes albopictus: risk factors for arbovirus pandemics. Vector Borne Zoonotic Dis. 20: 71-81.

Maciel-de-Freitas, R., Marques, W.A., Peres, R.C., Cunha, S.R.P. and Lourenc,o-de-Oliveira, R. 2007. Variation in Aedes aegypti (Diptera: Culicidae) container productivity in a slum and a suburban district of Rio de Janeiro during dry and wet seasons. Mem. Inst. Oswaldo Cruz. 102: 489-496.

Mahmood, B.A.I. and Mahmood, S.A.I. 2011. Emergence of Dengue in Bangladesh a major international public health concern in recent years. JERM, 2: 35-41.

Muraduzzaman, A.K.M., Alam, A.N., Sultana, S., Siddiqua, M., Khan, M.H., Akram, A., et al. 2018. Circulating dengue virus serotypes in Bangladesh from 2013 to 2016. Virus Dis. 29: 303-307.

Pontes, R.J., Freeman, J., Oliveira-Lima, J.W., Hodgson, J.C. and Spielman, A. 2000. Vector densities that potentiate dengue outbreaks in a Brazilian city. Am. J. Trop. Med. 62: 378-383.

Rahman, M., Rahman, K., Siddque, A.K., Shoma, S., Kamal, A.H.M., Ali, K.S., Nisaluk, A. and Breiman, R.F. 2002. First outbreak of dengue hemorrhagic fever, Bangladesh. Emerg. Infect. Dis. 8: $738-740$.

Richards, S.L. (2005). Spatial ecology of Aedes albopictus in suburban landscapes of a piedmont community in North Carolina Ph.D. Thesis, North Carolina State University, USA.

Saifur, R.G.M. and Chowdhury, A.K. 2020. Report on Aedes surveillance (Feb 3-Feb 19) in Dhaka South City Corporation (DSCC), Bangladesh. Report submitted to DSCC Health Department.

Saifur, R.G.M., Dieng, H., Hassan, A.A., Salmah, M.R.C., Satho, T., Miake, F., and Hamdan A. 2012. Changing domesticity of Aedes aegypti in northern peninsular Malaysia: reproductive consequences and potential epidemiological implications. PLoS One, 7(2), e30919.

Saifur, R.G.M., Hassan, A. A., Dieng, H., Salmah, M.R.C., Saad, A. R. and Satho, T. 2013. Temporal and spatial distribution of dengue vector mosquitoes and their habitat patterns in Penang Island, Malaysia. J. Am. Mosq. Control Assoc. 29: 33-43.

Saifur, R.G.M., Islam, I. and Hossain, B. 2016. First Record of Dengue Vector Aedes Aegypti in Gazipur City Corporation, Bangladesh. 6th Int'l Conference on Agriculture, Environment and Biological Sciences (ICAEBS'16) Dec. 21-22, 2016 Kuala Lumpur (Malaysia).pg. 131-135.

Shirin, T., Muraduzzaman, A.K.M., Alam, A.N., Sultana, S., Siddiqua, M., Khan, M.H., et al. 2019. Largest dengue outbreak of the decade with high fatality may be due to reemergence of DEN-3 serotype in Dhaka, Bangladesh, necessitating immediate public health attention. New Microbes New Infect. 29:100511.

Slaff, M. and Apperson, C. 1989. A key to the mosquitoes of North Carolina and the Mid-Atlantic states. 1989. The North Carolina Agriculture Extension Service Raleigh, NC, AG-412, 1-38.

Soper F.L. 1967. Aedes aegypti and yellow fever. Bull. World Health Organ. 36: 521-527. 
Tanaka K, Mizusawa K, Saugstad ES. 1979. A revision of the adult and larval mosquitoes of Japan (including the Ryukyu Archipelago and the Ogasawara Islands) and Korea (Diptera: Culicidae). Contrib. Am. Entomol. Inst. 16:1-979.

The Somokal 2019. Dengue is out of control. August 1, 2019. https://samakal.com/bangladeshothers/article/190814. Accessed: 04 November, 2020.

Tinker, M.E., Stojanovich, C.J. 1962. Identification of the pupae of receptacle-breeding mosquitoes. Ann. Entomol. Soc. Am. 55: 577-582.

Yunus, E.B. (2000). Dengue outbreak 2000: the emerged issues. Bangladesh Med. J. 33: 46-47.

Yunus, I.B., Banu, D., Talukder, K.R., Chowdhury, M., Bangali, A.M., \& Montanari, R.M. 2002. Sero-epidemiological Study of Dengue/Dengue Haemorrhagic Fever in a Metropolitan Hospital in Bangladesh. Dengue Bull. 26:1-6.

(Manuscript received on 10 November, 2020 revised on 20 December, 2020) 